\title{
Assembling a geospatial database of tsetse-transmitted animal trypanosomosis for Africa
}

Giuliano Cecchi ${ }^{* *}$, Massimo Paone ${ }^{2}$, Udo Feldmann $^{3}$, Marc JB Vreysen ${ }^{3}$, Oumar Diall ${ }^{1}$ and Raffaele C Mattioli ${ }^{2}$

\begin{abstract}
Background: African animal trypanosomosis (AAT), or nagana, is widespread within the tsetse-infested belt of sub-Saharan Africa. Although a wealth of information on its occurrence and prevalence is available in the literature, synthesized and harmonized data at the regional and continental scales are lacking. To fill this gap the Food and Agriculture Organization of the United Nations (FAO) launched the Atlas of tsetse and AAT, jointly implemented with the International Atomic Energy Agency (IAEA) in the framework of the Programme Against African Trypanosomosis (PAAT).

Methods: The Atlas aims to build and regularly update a geospatial database of tsetse species occurrence and AAT at the continental level. The present paper focuses on the methodology to assemble a dynamic database of AAT, which hinges on herd-level prevalence data as estimated using various diagnostic techniques. A range of ancillary information items is also included (e.g. trypanosome species, survey period, species and breed of animals, husbandry system, etc.). Input data were initially identified through a literature review.
\end{abstract}

Results: Preliminary results are presented for Ethiopia, Kenya and Uganda in East Africa: 122 papers were identified and analyzed, which contained field data collected from January 1990 to December 2013. Information on AAT was extracted and recorded for 348 distinct geographic locations. The presented distribution maps exemplify the range of outputs that can be directly generated from the AAT database.

Conclusions: Activities are ongoing to map the distribution of AAT in all affected countries and to develop the tsetse component of the Atlas. The presented methodology is also being transferred to partners in affected countries, with a view to developing capacity and strengthening data management, harmonization and sharing. In the future, geospatial modelling will enable predictions to be made within and beyond the range of AAT field observations. This variety of information layers will inform decisions on the most appropriate, site-specific strategies for intervention against AAT. Data on the occurrence of human-infective trypanosomes in non-human hosts will also provide valuable information for sleeping sickness control and elimination.

Keywords: African animal trypanosomosis, GIS, Atlas, Kenya, Uganda, Ethiopia, Tsetse, Glossina, Epidemiology, Zoonosis

\footnotetext{
* Correspondence: giuliano.cecchi@fao.org

${ }^{1}$ Food and Agriculture Organization of the United Nations (FAO),

Sub-regional Office for Eastern Africa, Addis Ababa, Ethiopia

Full list of author information is available at the end of the article
} 


\section{Résumé}

Introduction: La trypanosomose animale africaine (TAA), aussi appelée nagana, est largement répandue dans les zones d'Afrique sub-saharienne infestées par les glossines. Malgré la grande quantité d'informations disponibles dans la littérature sur sa répartition et prévalence, les données synthétisées et harmonisées aux niveaux régional et continental sont inexistantes. Pour faire face à ce problème, I'Organisation des Nations Unies pour l'alimentation et l'agriculture (FAO) a ouvert un chantier sur l'Atlas des glossines et de la TAA, exécuté conjointement avec l'Agence Internationale de l'Energie Atomique (AIEA) dans le cadre du Programme de Lutte contre la Trypanosomose Africaine (PLTA).

Méthodes: L'Atlas vise à créer et mettre à jour régulièrement une base de données spatialisée au niveau continental sur l'infection trypanosomienne animale et sur les différentes espèces de glossine. Cet article se concentre sur la méthodologie pour développer une base de données dynamique de la TAA, qui repose sur des données de prévalence au niveau du troupeau estimée par différentes techniques de diagnostic. Plusieurs informations supplémentaires sont incluses (ex. espèce de trypanosomes, date de collecte des données, espèce et race des animaux et système d'élevage, etc.). Dans une première phase de développement, les données à utiliser ont étés identifiées à travers un examen systématique de la littérature publiée.

Résultats: Cet article présente les résultats préliminaires pour l'Ethiopie, le Kenya et l'Ouganda en Afrique de l'Est : 124 articles ont été identifiés et analysés, qui contiennent des données de terrain collectées entre Janvier 1990 et Décembre 2013. Les informations sur la TAA ont été extraites et enregistrées pour 348 localités différentes. Les cartes de répartition ici présentées donnent un exemple des couches d'information pouvant être générées directement à travers l'Atlas.

Conclusions: Les activités sont en cours pour cartographier la TAA dans tous les pays affectés, et pour développer la composante 'glossines' de l'Atlas. La méthodologie ici présentée est en train d'être transférée aux partenaires dans les pays affectés, dans le but de développer les capacités et de renforcer la gestion, I'harmonisation et le partage des données. Dans le futur, la modélisation géospatiale permettra de faire des prédictions soit à l'intérieur soit au-delà des observations de terrain. Cet éventail de couches d'information doit éclairer les décisions sur les stratégies d'intervention contre la TAA les plus appropriées pour chaque site. Les données sur l'infection des animaux avec des trypanosomes zoonotiques seront également de grande valeur pour la lutte et l'élimination de la maladie du sommeil.

\section{Background}

African animal trypanosomosis (AAT), also known as nagana, refers to a group of vector-borne parasitic diseases of ruminants, camels, equines, swine and carnivores [1]. The aetiological agents (several species of unicellular flagellates called trypanosomes) are transmitted by the infected bite of the tsetse fly (Genus: Glossina). The disease causes heavy direct losses to livestock keepers as measured by mortality, morbidity and reduced productivity at the herd level. In the deprived rural settings where it occurs, AAT further reduces food security by limiting the exploitation of animal draught power and by constraining the optimal utilization of fertile lands [2]. Nagana is widely distributed across the tsetse-infested belt of sub-Saharan Africa, where approximately 60 million cattle are estimated to be at risk of infection over an area of about 10 million $\mathrm{km}^{2}$ [3]. Sleeping sickness, or human African trypanosomosis (HAT), is the human form of the disease, which occurs in more circumscribed foci of endemicity $[4,5]$ and 70 million people are estimated to be at risk of contracting the disease $[5,6]$.

After a long period of neglect, during the last 15 years ambitious initiatives have been trying to address the problem of tsetse-transmitted trypanosomosis in its continental dimension.

In 1997, the Programme against African Trypanosomosis (PAAT) was established to assist affected African countries in their efforts to control and eventually eliminate the disease [7]. PAAT brought together the efforts of the Food and Agriculture Organization of the United Nations (FAO), the World Health Organization (WHO), the International Atomic Energy Agency (IAEA) and the African Union Interafrican Bureau for Animal Resources (AU-IBAR). At the same time, resolutions of the World Health Assembly prompted WHO to strengthen its support to countries affected by sleeping sickness $[8,9]$, with the objective to eliminate HAT as a public health problem and to establish sustained surveillance systems in all endemic countries. Finally, successive decisions of the Heads of State and Government of the African Union in 2000 (AHG/156 - XXXVI) and 2001 (AHG/169 XXXVII) endorsed and committed to the plan of action for the Pan-African Tsetse and Trypanosomosis Eradication Campaign (PATTEC) [10].

If sound decisions are to be made, these important initiatives need reliable epidemiological information at a range of 
spatial scales. For example, spatially-explicit evidence is necessary to select priority areas for intervention [11], both where disease control can be regarded as a cost-effective option [12,13], and where the elimination of the tsetse fly vector appears as a feasible and sustainable endeavour [14].

In order to meet this need for harmonized and comprehensive spatial information, a recent WHO/FAO initiative in the framework of PAAT (i.e. the Atlas of HAT), has focused on the systematic mapping of HAT occurrence $[4,15,16]$ and risk $[6,17]$. In a related activity, a comprehensive and spatially-explicit dataset has also been assembled for sleeping sickness cases reported from nonendemic countries [18].

Despite a compelling need, the substantial progress made in mapping HAT has not yet been matched by comparable advances in the continental mapping of tsetse and AAT [3]. Tsetse distribution maps at the African level are old $[19,20]$ and continental maps of AAT have never been generated [3]. This knowledge gap poses serious constraints to evidence-based decision-making, and severely limits the possibility to assess the progress towards the goals set by various stakeholders at the continental level.

In an effort to fill this gap, FAO launched the Atlas of tsetse and AAT, an initiative to which IAEA has adhered to in the framework of PAAT [21,22]. Its immediate goal is to assemble contemporary, georeferenced data on the occurrence of Glossina species and AAT in sub-Saharan Africa. The present paper focuses on the AAT component and describes the methodology developed to assemble a database of AAT distribution. Preliminary results are presented for three east African countries, i.e. Ethiopia, Kenya and Uganda, and the way forward is outlined.

\section{Methods}

The general approach adopted to build the Atlas of tsetse and AAT is summarized in Figure 1. In essence, all publications and input data derived from the various sources are collated and stored in a centralized data repository. Subsequently, selected information items are extracted from the sources, harmonized and entered into a geo-spatial database. The database is structured into three simple tables, which are devoted to data sources, geographical data and epidemiological information respectively. The data abstraction protocol is described in detail in the Additional file 1, and it is an adaptation of similar work carried out for malaria [23]. Geographic Information Systems (GIS) enable distribution maps to be generated directly from the geo-database, while geospatial modelling will be used in the future to make predictions on tsetse and AAT distribution within and beyond the range of field observations.

At the present first stage of development, the Atlas is focusing on information published in peer-reviewed articles from scientific journals. Grey literature and additional unpublished datasets will be addressed at a later stage.

\section{Data sources}

The search strategy used to identify suitable scientific publications makes use of internet libraries, archives and indexes. In particular, the PAAT Tsetse and Trypanosomosis Information Bulletin (http://www.fao.org/ag/ againfo/programmes/en/paat/ttiq.html), PubMed Central (http://www.ncbi.nlm.nih.gov/pubmed/) and CabDirect (http:// www.cabdirect.org/) are the main tools used for data search. A temporal criterion of inclusion was applied, in that papers were only taken into consideration if containing field data collected from January 1990 onwards.

For each identified data source, a file is stored in the data repository, and a record is created in the 'Data sources' table of the AAT geo-database. The record includes a unique numerical identifier for the data source, the names of the authors, as well as the title and the year of publication. The study country is also noted, alongside external and internal links - the former corresponding to a URL (i.e. internet address of the paper), and the latter to an internal link to the respective PDF file in the data repository. The 'Data sources' table is completed with information on the type of spatially-explicit data the paper contains (i.e. data on animal trypanosomosis, on tsetse occurrence, or both). This latter flag enables papers to be rapidly selected for data extraction for the AAT and the tsetse components of the Atlas.

\section{Geographical data}

The table for geographical data is designed to capture information on the locations of epidemiological relevance, as described and referred to in the data sources. In particular, the table for geographic data includes: a unique numeric identifier of the location, the location name, the geographic coordinates (i.e. latitude and longitude, based on the WGS84 datum), the country name and the names of lower-level administrative units (provinces, districts, etc.). Each location is identified by a single set of coordinates, and therefore it is represented as a point entity in the GIS. If not available in the papers, geographic coordinates are searched from a variety of sources, including many publicly available gazetteers [15].

Although represented as point entities, the epidemiological data referring to the different locations will always have a bidimensional area of applicability. For example, if all animals sampled in a survey come from a single village and they are managed sedentarily, the survey point will probably refer to an area of a few square kilometres. By contrast, if a source reports the AAT prevalence for a whole district, it is the centroid of the district that will identify the survey in the database and in the GIS, and that point will be representative of a broader area. If 


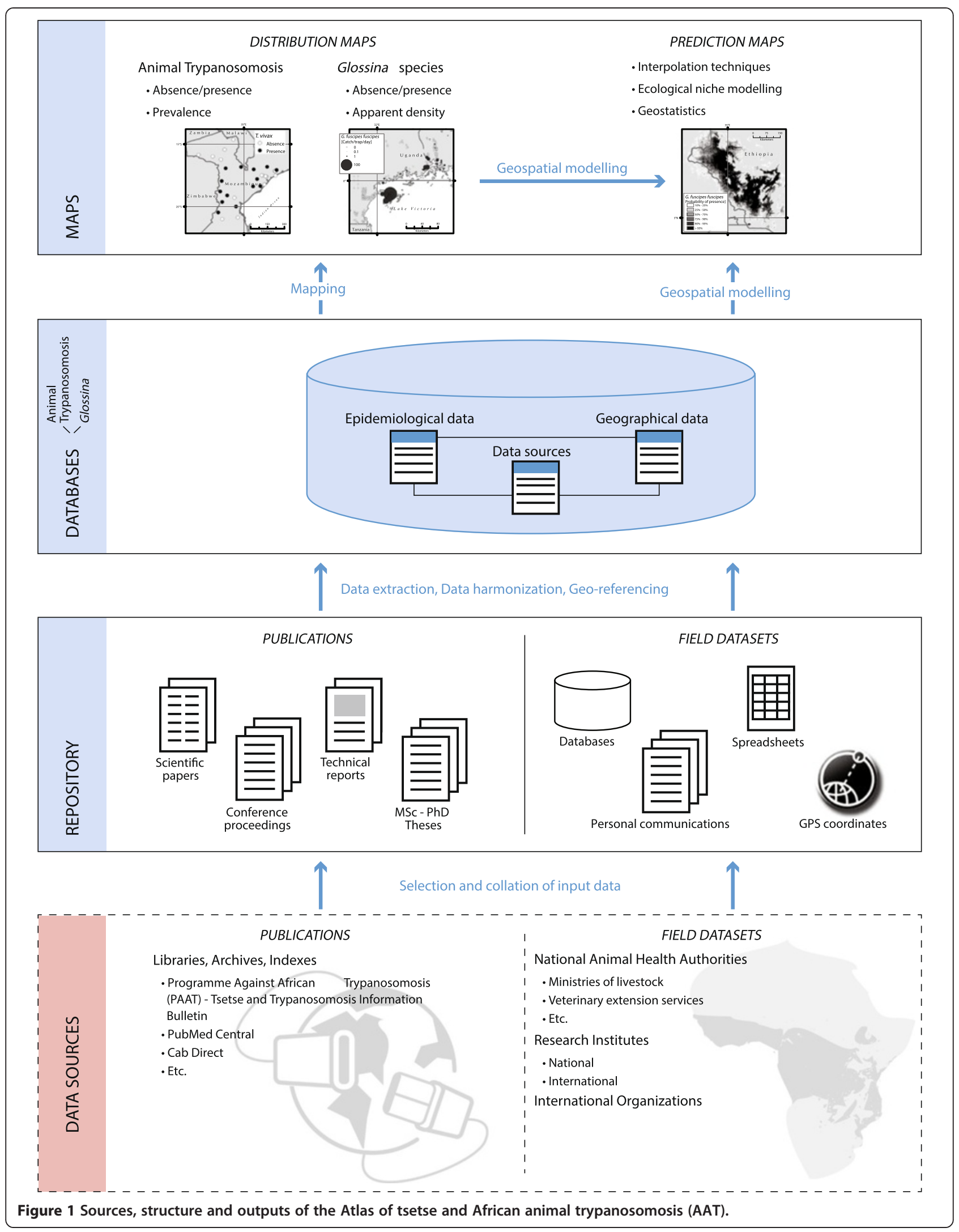


available, the exact surface area of the survey is recorded in the database (in $\mathrm{km}^{2}$ ). However, in most cases the data source (i.e. the paper) only enables the size of the study area to be estimated with a degree of approximation. Therefore, six broad categories were defined: $\leq 10 \mathrm{~km}^{2},>10$ and $\leq$ $25 \mathrm{~km}^{2},>25$ and $\leq 100 \mathrm{~km}^{2},>100$ and $\leq 500 \mathrm{~km}^{2}$, > 500 and $\leq 1,000 \mathrm{~km}^{2}$, and $>1,000$ and $\leq 10,000 \mathrm{~km}^{2}$. Lastly, if the geographic information included in the paper is so vague, or so widely spread, that it does not even fall in the last category, the related epidemiological data are not considered and are excluded from the Atlas.

\section{Epidemiological data}

The table containing epidemiological data is the cornerstone of the AAT database. Each record is structured as follows: a unique identifier of the survey, the survey period, diagnostic method, sample size, animal species, animal breed, age range, sex and husbandry system. Note is taken on whether the sample can be considered random, and therefore representative of the population of the area as a whole. Also, information on recent or ongoing interventions against tsetse and on the use of trypanocidal drugs is recorded. In this context, recent interventions are those implemented in the few years preceding the survey. Trypanosomal infections can be captured in terms of presence/absence, estimated prevalence and number of infected animals. Each record also includes identifiers for the geographic location and for the source, which enable the epidemiological records to be linked to the complementary information in the tables 'Data Sources' and 'Geographical data'.

More details are provided below on such relevant aspects as the species of hosts and parasites that are considered in the Atlas, and on diagnostic methods.

\section{Hosts and parasite species}

The range of animal hosts selected for inclusion in the Atlas of AAT is wide, and comprises all domestic and wild vertebrates for which data can be identified. This includes cattle, sheep, goats, pigs, horses, donkeys, mules, camels, dogs, as well as a number of wild animals including reptiles. Vertebrate hosts for which trypanosomal infection may not have a direct economic impact were included to gain insights into the epidemiological significance of the different reservoirs.

Concerning the parasite species, the causative agents of nagana include several species of tsetse-transmitted trypanosomes. Four species of major veterinary importance are recognized, and they are therefore selected for inclusion in the Atlas of AAT: Trypanosoma vivax (subgenus Duttonella), T. congolense and T. simiae (sub-genus Nannomonas) and T. brucei (sub-genus Trypanozoon). Although rarely reported, T. suis (sub-genus Pycnomonas), a swine-specific trypanosome [1], is also included in the database. Information on the occurrence of the different subgroups (or types) of T. congolense (namely savannah, forest/riverine and Kenya coast/kilifi) is also recorded when biochemical and molecular tools have enabled this level of characterization (the three subgroups of $T$. congolense being morphologically indistinguishable). A similar approach is applied to record the Tsavo strain of T. simiae [24,25], initially classified as another type of $T$. congolense [26]. Within T. brucei, three sub-species are recognized, among which $T . b$. brucei is the one with major veterinary importance. However, because of their epidemiological relevance as causative agents of sleeping sickness, the two human-infective subspecies (i.e. T. b. gambiense and T. $b$. rhodesiense) are also included in the Atlas of AAT if reported from non-human vertebrate hosts.

By contrast, $T$. godfreyi, which infects the same swine hosts as T. simiae but is less pathogenic, is not included in the database as it has only been isolated naturally from tsetse [27,28]. Also, non-tsetse-transmitted trypanosomes such as T. evansi (causing the wasting disease Surra) and T. equiperdum (responsible for dourine, a disease of equines), which have a much broader geographic distribution than AAT, are not included in the Atlas.

As a rule, efforts are also made to record in the database all types of mixed infections (i.e. animals found to be infected with more than one species/sub-species/ subgroup of trypanosomes). However, refinement of this component of the database might be needed because of the challenges posed by the very high number of possible combinations of mixed infections (especially when molecular tools are used for diagnosis).

\section{Diagnostic methods}

A criterion of inclusiveness guided the choice of the diagnostic methods. All methods that are capable of demonstrating past or present trypanosomal infections, either directly or indirectly, were considered. These comprise parasitological diagnostics, sub-inoculation methods, immunological tests and molecular methods [29].

Parasitological diagnosis is predicated on the direct observation of trypanosomes in the body fluids of affected animals. In the field or in the laboratory, with the aid of a microscope, a drop of blood can be examined for the presence of trypanosomes in the wet blood film technique. Fixed blood films can be examined (Giemsastained thick and thin smears), and concentration techniques can be applied to increase the sensitivity of the diagnosis - i.e. the haematocrit centrifugation technique (HCT) [30], subsequently improved in the buffycoat technique (BCT) [31]. Less utilized parasitological techniques include the miniature anion-exchange columns (MAECT) [32].

Sub-inoculation methods are based on the transfer of infection from a suspected case to another susceptible 
vertebrate host (animal sub-inoculation), to an invertebrate host (xenodiagnosis), or to an in vitro culture [29]. The latter category includes the kit for in vitro isolation of trypanosomes (KIVI) [33], originally developed for the isolation of the human infective $T . b$. gambiense and later applied also to AAT.

In immunological diagnosis, the detection of antibodies or antigens replaces the detection of parasites that characterizes parasitological methods. For the diagnosis of AAT these methods include the rarely used complement fixation test (CFT) [34], the indirect fluorescent antibody test (IFAT) [35], and the card agglutination trypanosomosis test (CATT) [36] - the latter being widely used for sleeping sickness. More widely used in the veterinary field is the enzyme-linked immunosorbent assay (ELISA), in particular the indirect ELISA for antibody detection (Ab-ELISA) [37]. In contrast, the antigendetection ELISA (Ag-ELISA) [38,39] failed to live up to its early promises [29] and it is no longer utilized in the field of AAT diagnosis.

Molecular tools, based on the detection of nucleic acids (DNA and RNA), constitute the last category of methods for detecting livestock-infective trypanosomes. Characterized by a very high sensitivity, these tools include the DNA hybridization and most notably the polymerase chain reaction (PCR). Two groups of PCR can be distinguished in AAT diagnosis: species-specific [40], and multiple-species [41], the main advantage of the latter being a less costly and time-consuming application. Importantly, the identification of the serum resistanceassociated (SRA) gene as a molecular marker of $T . b$. rhodesiense [42] enables detection of human-infective trypanosomes in non-human hosts $[43,44]$.

The lack of specificity in the clinical signs of AAT prevents definite clinical diagnosis, which is therefore not considered in the Atlas. By contrast, the packed cell volume $(\mathrm{PCV})$ is often measured in AAT epidemiological studies as a measure of anaemia, and therefore it is included in the database. If available from the data source, the average PCV is recorded for the herd as a whole, as well as separately for the AAT-positive and AAT-negative animals.

\section{Data processing}

In the process of data extraction, each data source is analyzed independently by two persons. For a number of information items, the text of the paper is reproduced verbatim in the database. This is the case, for example, for the description of the diagnostic method, the husbandry system and the presence of recent or ongoing interventions against tsetse and AAT in the study area. This literal recording enables the full wealth of information contained in the paper to be retained. Subsequently, harmonization enables the heterogeneous descriptive information to be lumped into broad categories for easier data extraction. For example, harmonization in the description of diagnostic methods enables diagnosticspecific data subsets to be easily generated for such methods as BCT, ELISA or PCR.

Notes are taken throughout the database to capture relevant nuances and, lastly, possible questions and requests for clarifications to the authors of the papers are recorded, which have the potential to contribute to the future refinement and improvement of the database.

\section{Results}

As we write, a total of 122 peer-reviewed publications have been identified, downloaded and processed, which contain spatially-explicit data on AAT collected since January 1990 in Ethiopia, Kenya and Uganda (49, 44, and 31 papers respectively, the sum exceeding the total because a few papers have a multinational scope). The complete list of publications is provided in the Additional file 2.

These 122 sources provided epidemiological information for 348 distinct geographic locations in Ethiopia (146), Kenya (103) and Uganda (99).

Figure 2 shows the resulting map of AAT occurrence in the three study countries. This is a comprehensive map that includes all species of vertebrate hosts, all diagnostic methods and all species of animal-infective, tsetse-transmitted trypanosomes (T. vivax, T. congolense, T. simiae, T. brucei and T. suis). Locations where AATcausing trypanosomes were not detected are recorded in the database, but they are not shown in Figure 2. This is because data on the absence of detection always need more contextual information to be properly interpreted. In other words, geographic locations reporting absence of detection of AAT may provide a misleading message unless information is also provided on such relevant aspects as the number and species of animals tested and the diagnostic method used.

Absence data can arguably be integrated in a more informative manner in such maps as those presented in Figure 3. In these maps, as opposed to Figure 2, focus is placed on livestock hosts (i.e. cattle, sheep, goats, pigs, horses, donkeys, mules and camels), on specific diagnostic methods (i.e. HCT and BCT), as well as on selected trypanosome species (i.e. T. vivax, T. congolense and T. brucei). A threshold is also applied to the minimum number of animals tested in the survey (i.e. 30).

In addition to absence of detection/presence maps, prevalence maps can also be generated. In Figure 4, the prevalence of cattle trypanosomosis is shown, as estimated with three different categories of diagnostic methods: parasitological (HCT and BCT) (a), immunological (Ab-ELISA) (b) and molecular (PCR) (c). 


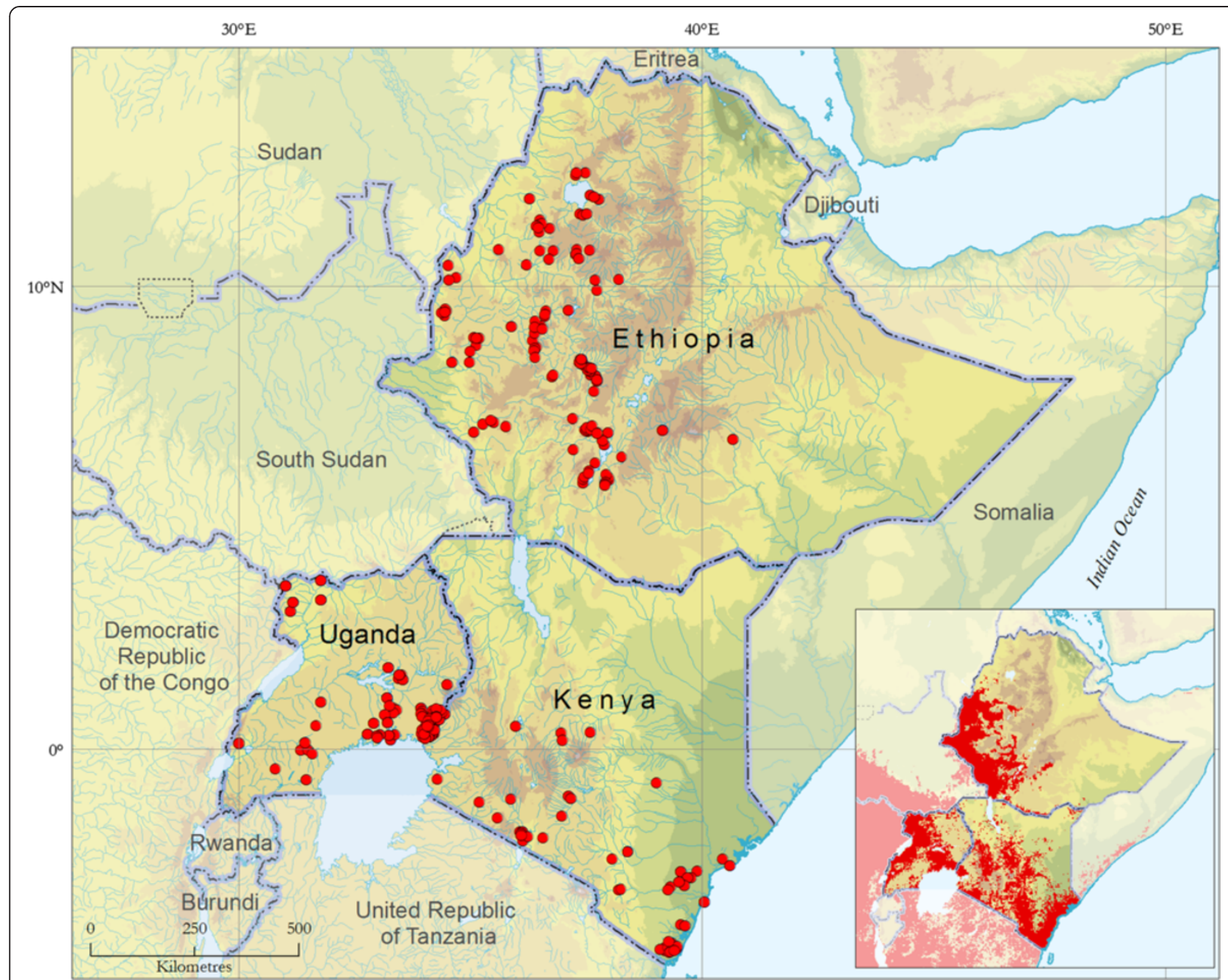

Figure 2 The occurrence of African animal trypanosomosis in Ethiopia, Kenya and Uganda. Reporting period: January 1990 - December 2013. Data were extracted from peer-reviewed scientific papers. The inset shows the predicted distribution of tsetse flies $[45,46]$.

\section{Discussion}

The paper presents a methodology to assemble a continental database of tsetse-transmitted animal trypanosomosis for Africa. The pilot activity in Ethiopia, Kenya and Uganda is proof of concept that information is available in the literature and that technical tools are mature for continental maps of AAT to be generated and disseminated. Transparent communication of all the data sources used (Additional file 2) may enable scientists to point out supplementary scientific papers for inclusion. However, it is apparent that information gaps in numerous geographical areas will require additional, unpublished data sources to be utilized if a complete picture is to be derived.

Continued technical support by FAO and IAEA to tsetse-affected countries facilitates access to this broader base of contemporary field data on AAT (e.g. [47,48]), and it also permits dissemination of the methodology at the local level through a range of capacity development activities. The potential exists for affected countries to adopt the presented methodology and build national Atlases of tsetse and AAT, and activities in this direction are ongoing in a number of countries [49]. Also, data sharing tools are available through the PAAT Information System (e.g. FAO Geonetwork), which can be used to maximize dissemination of geospatial information on AAT [50].

Activities are ongoing at FAO to apply the presented methodology to all countries affected by nagana, and to develop the tsetse component of the Atlas. In the process of assembling data on the distribution of Glossina species, attention is also being given to trypanosomal infection in the tsetse vector, although these types of datasets are scant. Geo-referenced information on the occurrence of animal- and human-infective trypanosomes in tsetse flies will complement data on the occurrence of human and 


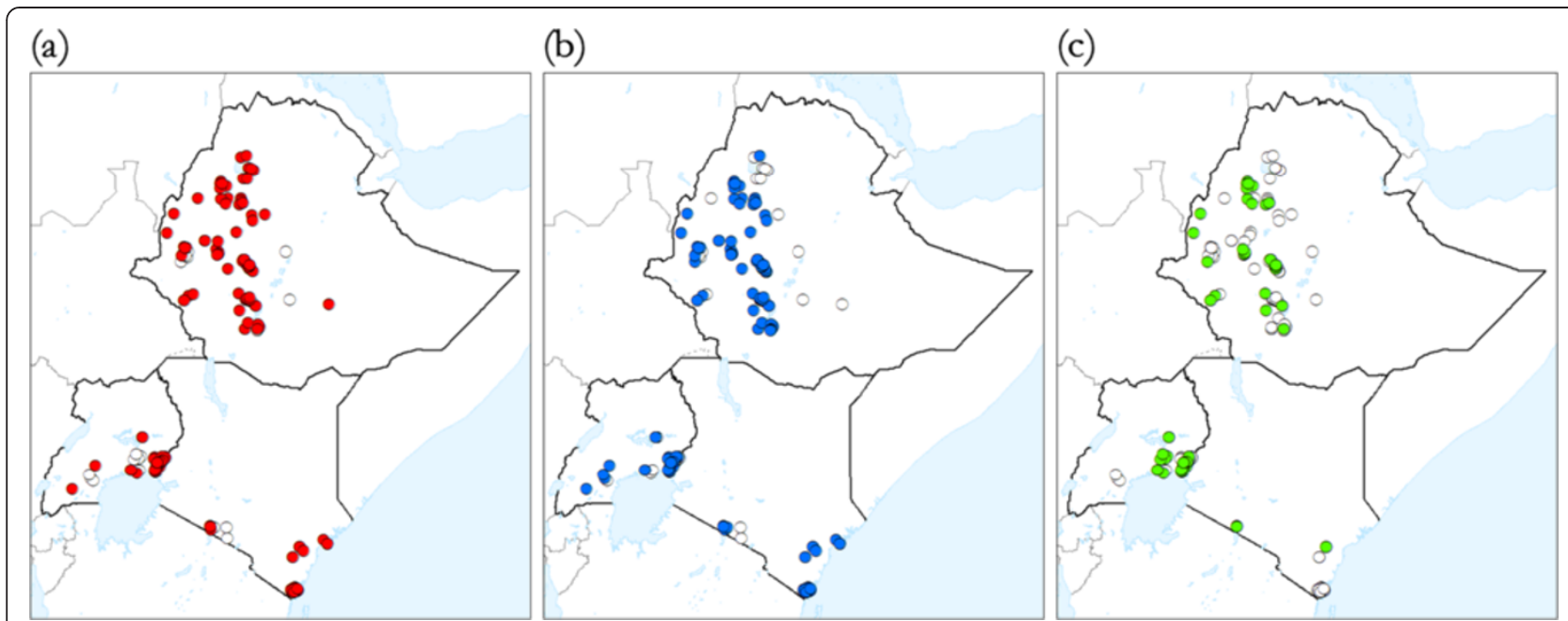

Figure 3 Absence of detection and presence of $T$. vivax (a), $T$. congolense (b) and $T$. brucei (c) in livestock. White circles: absence of detection. Coloured circles: presence. Diagnostic methods: haematocrit centrifugation technique (HCT) and buffy-coat technique (BCT). Minimum sample size: 30 animals. Reporting period: January 1990 - December 2013.

animal trypanosomoses, and will enable trypanosomal risk to be estimated from a broader perspective.

The present phase of data assembly and mapping will be followed by the application of geospatial modelling techniques in an effort to generate predictive surfaces of AAT endemicity and tsetse infestation at the national, regional and continental scales. In this process, particular attention will have to be paid to the many heterogeneities and potential sources of bias that follow from the diversity of approaches to data collection. Among these possible sources of bias we can cite the different sensitivities of the various diagnostic techniques, host susceptibility as it relates to host species, breed, age and sex, husbandry systems, trypanocidal usage, tsetse control and seasonality.

\section{Conclusions}

Developing contemporary global maps of AAT and tsetse will require substantial efforts, which can only be justified and sustained in the light of the broader objective of the Atlas initiative (i.e. to provide endemic countries with tools to better manage, analyze and share entomological and parasitological data, for improved, evidencebased decision making). To fulfil this broader objective, full engagement of and collaboration with the national animal health authorities and research institutes are crucial. In
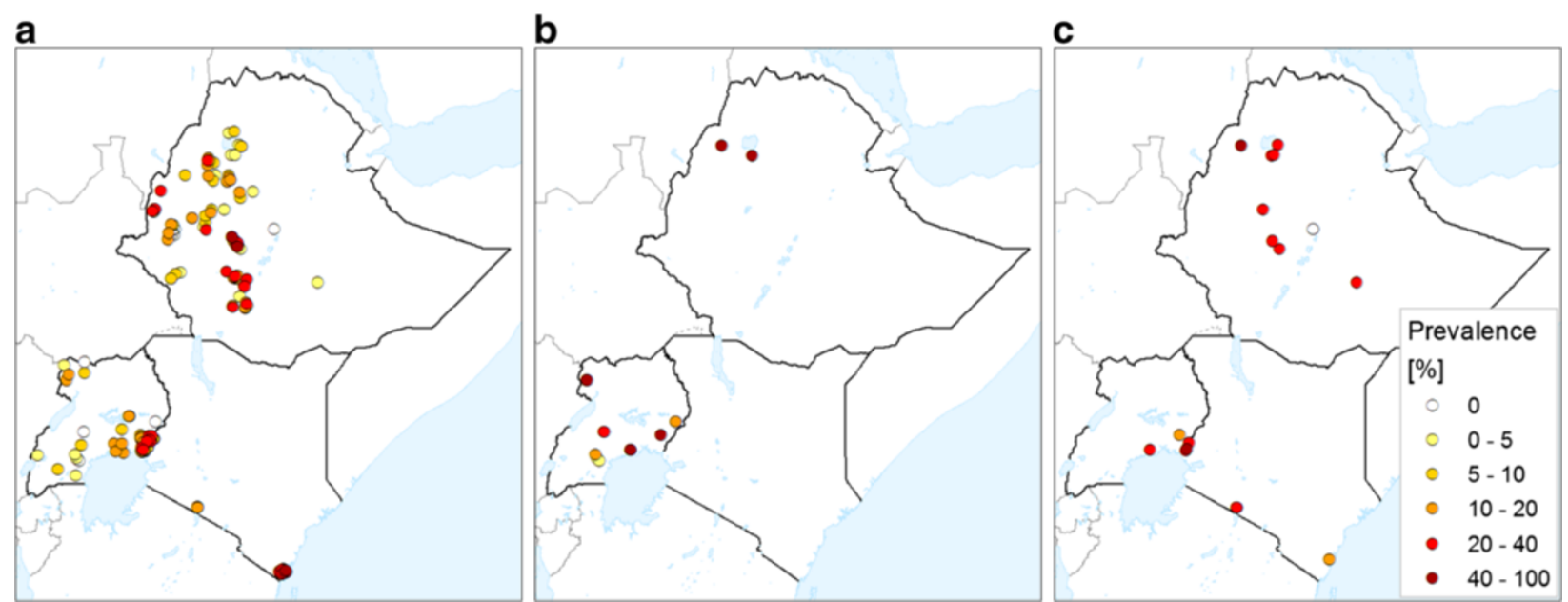

Figure 4 Prevalence of African animal trypanosomosis in cattle. Diagnostic methods: haematocrit centrifugation technique (HCT) and buffy-coat technique (BCT) (a), antibody detection enzyme-linked immunosorbent assay (Ab-ELISA) (b), polymerase chain reaction (PCR) (c). Minimum sample size: 30 animals. Reporting period: January 1990 - December 2013. 
particular, the highest priority is presently being given to supporting countries planning and implementing field interventions against trypanosomosis, with a focus on projects conducted in the framework of PATTEC.

\section{Additional files}

\section{Additional file 1: Protocol for the abstraction of African animal} trypanosomosis data. The protocol describes how data on the occurrence and prevalence of African animal trypanosomiasis are assembled into a geospatial database within the framework of the initiative "the Atlas of tsetse and African animal trypanosomiasis".

Additional file 2: List of papers analyzed to generate maps of African animal trypanosomosis in Ethiopia, Kenya and Uganda. Reporting period: January 1990 - December 2013. The list contains the 122 publications that have been identified as containing spatially-explicit data on African animal trypanosomosis collected since January 1990 in Ethiopia, Kenya and Uganda.

\section{Abbreviations}

AAT: African Animal Trypanosomosis; AU-IBAR: African Union Interafrican Bureau for Animal Resources; Ab-ELISA: Antibody-detection ELISA; Ag-ELISA: Antigen-detection ELISA; CATT: Card Agglutination Trypanosomosis Test; CFT: Complement Fixation Test; ELISA: Enzyme-Linked Immunosorbent Assay; FAO: Food and Agriculture Organization of the United Nations; GIS: Geographic Information Systems; HCT: Haematocrit Centrifugation Technique; HAT: Human African Trypanosomosis; IFAT: Indirect Fluorescent Antibody Test; IAEA: International Atomic Energy Agency; KIVI: Kit for In Vitro Isolation of Trypanosomes; MAECT: Miniature Anion-Exchange Columns; PCV: Packed cell volume; PATTEC: Pan-African Tsetse and Trypanosomosis Eradication Campaign; PCR: Polymerase Chain Reaction; PAAT: Programme against African Trypanosomosis; BCT: Buffy-Coat technique; WHO: World Health Organization.

\section{Competing interests}

The authors declare that they have no competing interests.

\section{Authors' contributions}

GC designed and coordinated the study, and drafted the manuscript. MP, GC and RCM selected the data. MP and GC processed the data. RCM, OD, UF and MJBV coordinated and supervised the collaboration between FAO and IAEA in the framework of PAAT. All authors have jointly conceptualized and contributed to the manuscript, and read and approved the final version of the submitted manuscript.

\section{Acknowledgments}

The Atlas of tsetse and African animal trypanosomosis is an initiative of the Food and Agriculture Organization of the United Nations (FAO), implemented in collaboration with the International Atomic Energy Agency (IAEA) in the framework of the Programme against African Trypanosomosis (PAAT). The Atlas is supported by the Government of Italy through the FAO Trust Fund for Food Security and Food Safety (Project GTFS/RAF/474/ITA 'Improving food security in sub-Saharan Africa by supporting the progressive reduction of tsetse-transmitted trypanosomosis in the framework of the NEPAD').

\section{Disclaimers}

The boundaries and names shown and the designations used on the maps presented in this paper do not imply the expression of any opinion whatsoever on the part of FAO and IAEA concerning the legal status of any country, territory, city or area or of its authorities, or concerning the delimitation of its frontiers or boundaries. Dotted lines on maps represent approximate border lines for which there may not yet be full agreement. The views expressed in this paper are those of the authors and do not necessarily reflect the views or policies of FAO and IAEA. (C) Food and Agriculture Organization of the United Nations

\section{Author details}

${ }^{1}$ Food and Agriculture Organization of the United Nations (FAO), Sub-regional Office for Eastern Africa, Addis Ababa, Ethiopia. 'Food and Agriculture Organization of the United Nations (FAO), Animal Production and Health Division, Rome, Italy. ${ }^{3}$ Joint Food and Agriculture Organization/ International Atomic Energy Agency Programme, Vienna, Austria.

Received: 21 December 2013 Accepted: 18 January 2014 Published: 21 January 2014

\section{References}

1. Taylor K, Authié EM-L: Pathogenesis of Animal Trypanosomiasis. In The Trypanosomiases. Edited by Maudlin I, Holmes P, Miles M. Wallingford, UK: CABI Publishing; 2004:331-353.

2. Shaw A, Cecchi G, Wint GRW, Mattioli R, Robinson T: Mapping the economic benefits to livestock keepers of intervening against bovine trypanosomosis in Eastern Africa. Prev Vet Med 2014, 113(2):197-210.

3. Cecchi G, Mattioli RC: Global geospatial datasets for African trypanosomiasis management: a review. In Geospatial datasets and analyses for an environmental approach to African trypanosomiasis. Edited by Cecchi G, Mattioli RC. Rome: Food and Agriculture Organization of the United Nations; 2009:1-39.

4. Simarro PP, Cecchi G, Paone M, Franco JR, Diarra A, Ruiz JA, Fèvre EM, Courtin F, Mattioli RC, Jannin JG: The Atlas of human African trypanosomiasis: a contribution to global mapping of neglected tropical diseases. Int J Health Geogr 2010, 9:57.

5. WHO: Control and surveillance of human African trypanosomiasis. In Technical Report Series. Geneva: World Health Organization; 2013.

6. Simarro PP, Cecchi G, Franco JR, Paone M, Fèvre EM, Diarra A, Ruiz JA, Mattioli RC, Jannin JG: Estimating and mapping the population at risk of sleeping sickness. PLoS Negl Trop Dis 2012, 6(10):e1859.

7. Hursey BS: The programme against African trypanosomiasis: aims, objectives and achievements. Trends Parasitol 2001, 17(1):2.

8. WHO: Resolution 50.36, 50 ${ }^{\text {th }}$ World Health Assembly. Geneva: World Health Organization; 1997.

9. WHO: Resolution 56.7, $56^{\text {th }}$ World Health Assembly. Geneva: World Health Organization; 2003.

10. Kabayo JP: Aiming to eliminate tsetse from Africa. Trends Parasito/ 2002, 18(11):473-475.

11. Mattioli R, Feldmann U, Hendrickx G, Wint W, Jannin J, Slingenbergh J: Tsetse and trypanosomiasis intervention policies supporting sustainable animal-agricultural development. J Food Agr Environ 2004, 2:310-314

12. Van den Bossche P, Delespaux V: Options for the control of tsetsetransmitted livestock trypanosomosis. An epidemiological perspective. Vet Parasitol 2011, 181(1):37-42.

13. Shaw AP, Torr SJ, Waiswa C, Cecchi G, Wint GR, Mattioli RC, Robinson TP: Estimating the costs of tsetse control options: an example for Uganda. Prev Vet Med 2013, 110(3-4):290-303.

14. Vreysen M, Robinson A, Hendrichs J (Eds): Area-wide control of insect pests: from research to field implementation. Dordrecht, The Netherlands: Springer; 2007.

15. Cecchi G, Paone M, Franco JR, Fèvre E, Diarra A, Ruiz J, Mattioli R, Simarro PP: Towards the Atlas of human African trypanosomiasis. Int J Health Geogr 2009, 8:15.

16. Cecchi G, Courtin F, Paone M, Diarra A, Franco JR, Mattioli RC, Simarro PP: Mapping sleeping sickness in Western Africa in a context of demographic transition and climate change. Parasite 2009, 16(2):99-106.

17. Simarro PP, Cecchi G, Franco JR, Paone M, Fèvre EM, Diarra A, Ruiz JA, Mattioli RC, Jannin JG: Risk for human African trypanosomiasis, Central Africa, 2000-2009. Emerg Infect Dis 2011, 17(12):2322-2324.

18. Simarro PP, Franco JR, Cecchi G, Paone M, Diarra A, Ruiz JA, Jannin JG: Human African trypanosomiasis in non-endemic countries (2000-2010). J Travel Med 2012, 19(1):44-53.

19. Ford J, Katondo KM: Maps of tsetse flies (Glossina) distribution in Africa, 1973 according to sub-generic groups on scale of 1:5 000 000. Bull Anim Health Prod Afr 1977, 25:187-193.

20. Katondo K: Revision of second edition of tsetse distribution maps: an interim report. Insect Sci Appl 1984, 5(5):381-388.

21. Cecchi G, Paone M, Feldmann U, Vreysen M, Mattioli R: Developing continental maps of African animal trypanosomosis. In $31^{\text {st }}$ Meeting of the International Scientific Council for Trypanosomiasis Research and Control 
(ISCTRC)12-16 October 2011. Bamako, Mali: African Union - Interafrican Bureau for Animal Resources (AU-IBAR); 2013.

22. Cecchi G, Paone M, Feldmann U, Vreysen M, Mattioli R: Developing continental maps of Glossina species. In $31^{\text {st }}$ Meeting of the International Scientific Council for Trypanosomiasis Research and Control (ISCTRC)12-16 October 2011. Bamako, Mali: African Union - Interafrican Bureau for Animal Resources (AU-IBAR); 2013.

23. Guerra C, Hay S, Lucioparedes L, Gikandi P, Tatem A, Noor A, Snow R: Assembling a global database of malaria parasite prevalence for the Malaria Atlas Project. Malar J 2007, 6(1):17.

24. Stevens JR, Noyes HA, Dover GA, Gibson WC: The ancient and divergent origins of the human pathogenic trypanosomes, Trypanosoma brucei and T. cruzi. Parasitology 1999, 118(1):107-116.

25. Gibson WC, Stevens JR, Mwendia CM, Ngotho JN, Ndung'u JM: Unravelling the phylogenetic relationships of African trypanosomes of suids. Parasitology 2001, 122(6):625-631

26. Majiwa PA, Maina M, Waitumbi JN, Mihok S, Zweygarth E: Trypanosoma (Nannomonas) congolense: molecular characterization of a new genotype from Tsavo, Kenya. Parasitology 1993, 106(2):151-162.

27. McNamara J, Mohammed G, Gibson W: Trypanosoma (Nannomonas) godfreyi sp. nov. from tsetse flies in The Gambia: biological and biochemical characterization. Parasitology 1994, 109(04):497-509.

28. Stevens J, Brisse S: Systematics of Trypanosomes of Medical and Veterinary Importance. In The Trypanosomiases. Edited by Maudlin I, Holmes P, Miles M. Wallingford, UK: Cabi Publishing; 2004:1-23.

29. Eisler M, Dwinger R, Majiwa P, Picozzi K, Maudlin I, Holmes P, Miles M: Diagnosis and epidemiology of African animal trypanosomiasis. In The Trypanosomiases. Edited by Maudlin I, Holmes P, Miles M. Wallingford, UK: CABI Publishing; 2004:253-267.

30. Woo P: The haematocrit centrifuge technique for the diagnosis of African trypanosomiasis. Acta Trop 1970, 27(4):384-386.

31. Murray M, Murray P, Mclntyre W: An improved parasitological technique for the diagnosis of African trypanosomiasis. Trans $R$ Soc Trop Med Hyg 1977, 71(4):325-326.

32. Lumsden W, Kimber C, Evans D, Doig S: Trypanosoma brucei: miniature anion-exchange centrifugation technique for detection of low parasitaemias: adaptation for field use. Trans R Soc Trop Med Hyg 1979, 73(3):312-317.

33. Aerts $D$, Truc $P$, Penchenier $L$, Claes $Y$, Le Ray $D$ : A kit for in vitro isolation of trypanosomes in the field: first trial with sleeping sickness patients in the Congo Republic. Trans R Soc Trop Med Hyg 1992, 86(4):394-395.

34. Lötzsch R, Deindl G: Trypanosoma congolense: III. Serological responses of experimentally infected cattle. Exp Parasitol 1974, 36(1):27-33.

35. Luckins A, Mehlitz D: Evaluation of an indirect fluorescent antibody test, enzyme-linked immunosorbent assay and quantification of immunoglobulins in the diagnosis of bovine trypanosomiasis. Trop Anim Health Pro 1978, 10(1):149-159.

36. Magnus E, Vervoort T, Van Meirvenne N: A card-agglutination test with stained trypanosomes (CATT) for the serological diagnosis of TB gambiense trypanosomiasis. Ann Soc Belg Med Trop 1977, 58(3):169-176.

37. Voller A, Bidwell D, Bartlett A: Enzyme immunoassays in diagnostic medicine: Theory and practice. Bull World Health Organ 1976, 53(1):55.

38. Rae $P$, Luckins A: Detection of circulating trypanosomal antigens by enzyme immunoassay. Ann Trop Med Parasitol 1984, 78(6):587-596.

39. Nantulya V, Musoke A, Rurangirwa F, Saigar N, Minja S: Monoclonal antibodies that distinguish Trypanosoma congolense, T. vivax and T. brucei. Parasite Immunol 1987, 9(4):421-431.

40. Moser DR, Cook GA, Ochs DE, Bailey CP, McKane MR, Donelson JE: Detection of Trypanosoma congolense and Trypanosoma brucei subspecies by DNA amplification using the polymerase chain reaction. Parasitology 1989, 99(Pt 1):57-66.

41. Desquesnes M, McLaughlin G, Zoungrana A, Davila AM: Detection and identification of Trypanosoma of African livestock through a single PCR based on internal transcribed spacer 1 of rDNA. Int J Parasitol 2001, 31(5-6):610-614

42. De Greef C, Chimfwembe E, Kihang'a Wabacha J, Bajyana Songa E, Hamers R: Only the serum-resistant bloodstream forms of Trypanosoma brucei rhodesiense express the serum resistance associated (SRA) protein. Ann Soc Belg Med Trop 1992, 72(Suppl 1):13-21.

43. Welburn SC, Picozzi K, Fevre EM, Coleman PG, Odiit M, Carrington M, Maudlin I: Identification of human-infective trypanosomes in animal reservoir of sleeping sickness in Uganda by means of serum-resistanceassociated (SRA) gene. Lancet 2001, 358(9298):2017-2019.

44. Gibson W, Backhouse T, Griffiths A: The human serum resistance associated gene is ubiquitous and conserved in Trypanosoma brucei rhodesiense throughout East Africa. Infect Genet Evol 2002, 1(3):207-214

45. Wint W, Rogers D: Predicted distributions of tsetse in Africa. Rome: Report of the Environmental Research Group Oxford Ltd and TALA Research Group. Department of Zoology, University of Oxford, for the Animal Health Service of the Animal Production and Health Division of the Food and Agriculture Organisation of the United Nations; 2000.

46. Wint GRW: Kilometre resolution Tsetse Fly distribution maps for the Lake Victoria Basin and West Africa: Report to the Joint Food and Agriculture Organization of the United Nations/International Atomic Energy Agency Programme. Rome: Food and Agriculture Organisation of the United Nations; 2001.

47. Adam Y, Marcotty T, Cecchi G, Mahama C, Solano P, Bengaly Z, Van den Bossche P: Bovine trypanosomosis in the Upper West Region of Ghana: entomological, parasitological, and serological cross-sectional surveys. Res Vet Sci 2012, 92:462-468.

48. Seck M, Bouyer J, Sall B, Bengaly Z, Vreysen M: The prevalence of African animal trypanosomoses and tsetse presence in Western Senegal. Parasite 2010, 17(3):257-265.

49. Ahmed SK, Rahman HMA, Cecchi G: The spatial distribution of bovine trypanosomosis in tsetse-infested areas of Sudan: past \& present. In $32^{\text {nd }}$ Meeting of the International Scientific Council for Trypanosomiasis Research and Control (ISCTRC)8-12 September 2013. Khartoum, Sudan: African UnionInterafrican Bureau for Animal Resources (AU-IBAR). in press.

50. Cecchi G, Mattioli R: FAO GeoNetwork in a Multinational Development Programme - the case of the Programme Against African Trypanosomiasis. OSGeo J 2007, 2:20-23.

doi:10.1186/1756-3305-7-39

Cite this article as: Cecchi et al:: Assembling a geospatial database of tsetse-transmitted animal trypanosomosis for Africa. Parasites \& Vectors 2014 7:39.

\section{Submit your next manuscript to BioMed Central and take full advantage of:}

- Convenient online submission

- Thorough peer review

- No space constraints or color figure charges

- Immediate publication on acceptance

- Inclusion in PubMed, CAS, Scopus and Google Scholar

- Research which is freely available for redistribution 